\title{
ORIENTAÇÃO SEXUAL NAS ESCOLAS: fato ou anseio?
}

\author{
Sandra A parecida de AL M EIDA a, Jordana de A Imeida N O GUEIRA b,
} Antonia Oliveira SILVA' ${ }^{c}$, Gilson Vasconcel os T ORRES ${ }^{d}$

\section{RESUM 0}

Pesquisa qual itativa que objetivou analisar sob a ótica dos educadores de escolas públicas do ensino fundamental, como o tema "orientação sexual" vem sendo incorporado nas práticas pedagógicas. Participaram do estudo 23 professores da rede municipal de ensino de Cajazeiras, Paraíba. Elegeu-se o g rupo focal como técnica de investigação, e os dados empíricos obtidos for am organizados mediante análise de conteúdo temática. Constatou-se que há um esforço dos atores em privilegiar conteúdos relativos à orientação sexual no ambiente escolar, porém esses debates exigem que preliminar mente seja incentivado um aprofundamento de caráter informativo e subjetivo sobre "sexualidade", propiciando aos educadores um espaço para re-significações de sua internalidade e valores. A informação direcionada ao cuidado de si deve extrapolar os limites preventivistas e higienistas, incorporando metodologias extensivas, inclusivas e reflexivas, que reconheçam os direitos humanos e sociais e favoreçam a construção ética da cidadania.

D escritores: Comportamento sexual. E ducação sexual. Sexualidade.

\section{RESUMEN}

La investigación cualitativa objetivó analizar las perspectivas de los educadores de escuelas públicas de educación básica y de cómo el tema "orientación sexual" se ha incor porado a las prácticas de enseñanza. L os participantes del estudio fueron 23 pr ofesores deescuelas munici pales de Cajaz eiras, P araíba, B rasil. F ueelegido el grupo focal como técnica de investigación, y los datos obtenidos fueron organizados por el análisis de contenido temático. Se encontró que hay un esfuerzo de los actores a favor de contenidos relacionados con la orientación sexual en el entorno escolar, pero eso requiere que las discusiones preliminares deban al entar una profundización de carácter subjetivo sobre "sexualidad", proporcionando a los educadores un espacio para la (re)significación de interioridad y sus valores. Información dirigida a los cuidados personales debe trascender los límites de prevención ehigiene, incorporando una metodología amplia, incl usiva y reflexiva, que reconoz ca los derechos humanos y promueva la construcción social y ética de la ciudadanía.

Descriptores: Conducta sexual. E ducación sexual. Sexualidad.

Título: O rientación sexual en las escuelas: ¿realidad 0 anhelo?

\section{ABST RACT}

T his qualitative research aims to analyze how sexual orientation has been incor porated into pedagogic practices through the point of view of educators from public schools of fundamental teaching. T wenty three educators from Cajazeiras, Paraíba, B razil, participated in the study. The focus group was elected as technique of investigation, and the empirical data obtained were organized according to the technique of analysis of content. It was realized that there is an effort of the actors to privilege contents related to sexual orientation in the school environment, though they demand that a level of informative and subjective character about the "sexuality" be encouraged, providing the educators with a space for resignifications of its internality of values. The information directed to self-care must transcend the limits of prevention and hygienisation, incorporating extensive, inclusive and reflective methodologies, which recognize human and social rights and promote the ethical construction of citizenship.

Descriptors: Sexual behavior. Sex education. Sexuality.

Title: Sexual orientation in the school environment: fact or eagerness?

\footnotetext{
a M estre em Enfermagem, D outoranda do Programa de Pós-Graduação em Enfermagem da U niversidade Federal da Paraíba (UF PB), Professora do Curso de Enfermagem da Faculdade de Enfermagem N ova E sperança (FACE N E), João Pessoa, Paraíba, Brasil.

${ }^{b}$ D outora E nfermagem e Saúde Pública, Professora do D epartamento de E nfermagem Clínica e do Programa de Pós-G raduação em E nfermagem da U F PB, João Pessoa, Paraíba, Brasil.

' D outora em Enfermagem F undamental, Professora do D epartamento de Enfermagem em Saúde Pública e Psiquiatria e do Programa de Pós-G raduação em Enfermagem da UFPB, João Pessoa, Paraíba, Brasil.

d D outor em Enfermagem Fundamental, Professor A ssociado do D epartamento de Enfermagem e do Programa de Pós-Graduação em Enfermagem da U niversidade Federal do Rio G rande do N orte (U F R N ), N atal, Rio Grande do N orte, Brasil.
} 


\section{INT RODUÇÃO}

$\mathrm{N}$ as últimas décadas a adolescência e a juventude vêm ocupando um lugar relevante no contexto das políticas públicas, especialmente com problemas que vêm atingindo os jovens de todo o planeta, como as D oenças Sexual mente T ransmissíveis (DST )/ aids, a gravidez precoce e 0 abor to inseguro.

A preocupação com a ocorrência desses fatores fez com que organismos oficiais, tais como $\mathrm{M}$ inistério da E ducação e Cultura (M EC) passassem a estimular projetos de orientação sexual nas escolas culminando no ano de 1996, na inclusão da temática como tema transver sal (T T ) nos Parâmetros Curriculares Nacionais ( $\mathrm{PCN}$ 's). Concebe-se que os órgãos formadores, caracterizam-se como espaços privilegiados nos quais é possível inserir por meio de processo educacional, a educação preventiva e efetiva, contribuindo positivamente no campo da saúde.

Foi proposto que a orientação sexual deveria ser articulada com diversas disciplinas e outros temas, tais como: ética, saúde, gênero, meio ambiente e pluralidade cultural. A tentativa de descentralizar o tema em diversos campos disciplinares se apresenta como uma forma de favorecer abordagens pluralistas e interdisciplinares. N esta perspectiva, haveria um envolvimento e comprometimento dos professores de todas as disciplinas, frente às manifestações expressas nas falas e nos comportamentos dos alunos. 0 enfoque pedagógico da orientação sexual nas escolas privilegiaria questões relacionadas ao gênero, à sexualidade e à afetividade ${ }^{(1)}$.

P articularmente, a inclusão da "O rientação Sexual", como TT demonstra um reconhecimento oficial quanto à importância da temática sexualidade nos espaços da educação for mal. Tendo como eixo norteador, a ética, a cidadania e os direitos humanos, as propostas de trabal ho elaboradas peIos PCN 's baseiam-se no pressuposto que, sendo a sexualidade complexa e multidimensional, não poderia ficar restrita a conteúdos formalistas e nem tão pouco às discussões das ciências naturais relacionadas somente a reprodução, reduzindo-a ao aspecto biológico(2).

Há de se considerar que no cenário brasileiro a inserção desta temática nos conteúdos curriculares ainda não se apresenta de forma legitimada. Se por um lado alguns grupos defendem a união "educação/ sexualidade", outros mantêm reservas quanto ao papel da escola na orientação sexual dos alunos.

A credita-se que essa divergência traz à tona implicações subjetivas da construção da sexualidade dos educadores: disponibilidade interna em abordar temas polêmicos per meados de valorações pessoais, temporais e culturais, em ampliar os espaços de vivências, estabelecendo relações extramuros e ainda, em resgatar e discutir o papel da escola e sua concepção pedagógica.

Portanto, o objetivo do presente estudo foi o de analisar a percepção dos educadores na inserção da orientação sexual em sua práxis pedagógica.

\section{METODOLOGIA}

T rata-se de estudo qualitativo envolvendo 23 professores de duas escolas publicas do ensino fundamental de Cajazeiras, Paraíba. E legeu-se o g rupo focal como técnica de investigação, cujo critério de organização fundamentou-se na composição de grupos de professores que compartilhassem o mesmo local de trabalho. I sso favoreceu os relatos de experiências, necessidades, valores e crenças.

Os dados coletados foram analisados com base na técnica de análise de conteúdo da enunciação que seguem as condições e organização de uma análise da enunciação, em que cada depoimento é estudado em si mesmo e considerados como uma totalidade organizada e singular ${ }^{(3)}$. E sta anál ise atendeu aos seguintes passos: constituição do corpus (constituído por três grupos focais) e preparação do material. Este último compreendeu: "alinhamento e a dinâmica do discurso que consiste em encontrar a lógica intrínseca que estrutura cada depoimento: análise sequencial; 0 estilo e os el ementos atípicos e as figuras de retórica"(3).

A pesquisa foi submetida à apreciação do Comitê de Ética e Pesquisa do Centro de Ciências da Saúde da U niversidade Federal da Paraíba, atendendo às orientações inerentes à Resolução 196/ 96 do Consel ho $\mathrm{N}$ acional de Saúde ${ }^{(4)}$, e aprovada sob o protocolo $\mathrm{n} \cong 1075$.

\section{APRESENT AÇÃO E DISCUSSÃO DOS RESULTADOS}

$\mathrm{N}$ o discurso oficial, contido nos PCN 's, as atitudes pedagógicas do educador, devem pautar-se no reconhecimento da legitimidade e licitude das 
expressões da sexualidade, manifestas pelas crianças e jovens ${ }^{(5)}$. T ais prerrogativas demandam do educador um contíguo de habilidades que transponham a visão de senso comum e que disponibilize aos mesmos, recursos para lidar com uma temática acima de sua própria carga de valores e visão de mundo ${ }^{(2)}$. Sabe-se, no entanto que o modo como 0 educador re(age) pedagogicamente é produto de uma concepção pré-estabelecida da sexualidade, sendo resultante de uma formação pessoal e profissional que antecedem seu momento docente.

Convêm analisar, portanto a responsabilidade que é direcionada ao educador, pois a exigência feita é grande, sendo necessário possuírem estraté gias metodológicas apropriadas para abordar esse assunto. E ssas dificuldades refletem as condições de trabalho dos educadores quando é referido 0 incipiente domínio do conteúdo por parte dos professores, associado à impropriedade e/ ou insuficiência de domínios de conteúdos escolares, manifestados pela inadequação de sua sel eção, sequenciação e desenvolvimento dos conteúdos e ainda com o agravante, o surgimento de relutância diante do processo de reflexão e raciocínio dos professores assim como os seus desdobramentos para a consolidação de práticas educativas(6).

E videnciou-se que as questões relativas à orientação sexual, ainda desafiam e provocam temores, uma vez que se trata de uma conversa interna, fato aparentemente agravado quando essa ocorre entre diferentes gerações - educadores(as)/ alunos (as).

[ ...] os valores maternos, a criação, tudo isso tá muito diferente hoje em dia [ ...] não foi assim que eu fui criada enão mear rependo [ ...] sou professora de ciências e tenho vergonha, quando chega na parte de mostrar aquilo fico morta, isso me incomoda [ ...] (A5).

Esse discurso corrobora com o "dispositivo sexual", quando é sustentado que o professor não obteve informações dentro de casa, mas que de alguma forma "fincou" um ideário sobre sexualidade de maneira restritiva.

$\mathrm{N}$ ota-se que as questões valorativas estão intrinsecamente abarcadas no conceito de sexualidade, porém as instruções para a conduta não se isolam como "regras" ou "normas", mas, antes, em referendos do bom e do mau comportamento, das coisas a serem feitas e evitadas ${ }^{(7)}$. E ssa afirmativa é observada nos discursos que seguem:
[ ...] eu acho que a dificuldade é dos educadores que não tem informação, nem querem ter [ ...] por vergonha, medo, sei lá [ ...] (A 8).

[ ...] se for preciso vou ter que me preparar muito, me sinto mal falando dessas coisas [ ...] sou tímida, falar com as crianças é bastante difícil pra mim [ ...] (A 5).

Falar sabre orientação sexual/ sexualidade é contrapor também uma reflexão acerca de sentimentos, emoções e afetos, fatores subjetivos fundamentais no desenvolvimento e na vida psíquica do ser humano.

Nesse sentido, o educador deveria estar preparado para propiciar debates, lidar com valores, tabus e preconceitos, mas, continua com subsídios internos insuficientes, para trabalhar essas questões e acabam dando a elas enfoque totalmente biológico com a função de se preservarem frente aos alunos com relação aos seus próprios questionamentos, receios e ansiedades, estigmas e tabus. É imprescindível que o educador ao trabalhar a orientação sexual na escola tenha capacidade/ disponibilidade de rever sua postura e seus conhecimentos constantemente.

Os próprios textos do PCN apontam que o educador tenha acesso à formação específica para tratar de sexualidade na escola, permitindo a construção de uma postura profissional e consciente na abor dagem da temática(5).

Neste contexto, procura-se desenvolver um sujeito com competências para ajudar ou encaminhar situações que surjam na sala de aula e no convívio com os al unos. $\mathrm{N}$ o entanto, solicita-se dos educadores, que tomem consciência sobre quais são os seus valores, crenças, opiniões e sentimentos que cultiva em relação à sexualidade para que desenvolva uma postura ética em sua atuação junto aos alunos ${ }^{(5)}$.

0 papel do educador é o de oferecer novos conhecimentos, experimentar questionamentos e possibilitar a interação de opiniões que favoreça as decisões individuais, oferecendo subsídios para 0 crescimento por meio da busca da verdade. $\mathrm{N}$ otase então, que se o educador se propuser a ensinar 0 certo ou errado, ele se colocará na posição de detentor da verdade, distanciando-se de seus al unos.

Para haver essa aproximação, é necessário que se estabel eça uma relação de confiança entre al uno e educador e que este deva apresentar-se com disponibilidade para conversar a respeito das questões apresentadas, não emitir valorações pessoais 
sobre as abordagens feitas pelos alunos e responder às perguntas de forma direta e esclarecedora. 0 educador apropriado para abordar o tema éaquele que está bem "adequado com sua sexualidade, tendo a coragem de desafiar seus próprios tabus e preconceitos, reconhecendo suas próprias falhas"(8).

Porém ao pensar o educador deve-se levar em consideração a existência de um tripé constituído por indivíduo, sociedade e instituição, e que o educador do século XXI precisa, mais do que nunca, ser uma referência para seus alunos, uma vez que suas atitudes em sala de aula ensinam tanto quanto ou mais que os conteúdos didáticos, levando-os a pensar um pouco mais sobre as questões éticas, sociais e políticas. E m sua prática, é necessário que o educador esteja atento para a sua função: de uma prática mobilizadora de outros saberes pedagógicos e conhecimentos que deveriam ser compartiIhados por meio de concepções reflexivas ${ }^{(9)}$.

D iante dessa per spectiva, a escola assume um local de destaque neste processo de inclusão da orientação sexual enquanto $T \mathrm{~T}$, uma vez que a convivência escolar é repleta de trocas que envolvem esta dimensão humana, portanto, as normas e condutas trabal hadas nesse ambiente interferem na construção da sexualidade de cada aluno individualmente; consequentemente ela é um espaço importante de conhecimento e transmissão de valores ${ }^{(10)}$.

Contudo, é necessário que se tenha a compreensão de que o educador é um sujeito, membro dessa sociedade, na qual a sexual idade é exposta e que se conforma como um tabu, diferentemente da proposta que é abordá-la sob um ol har mais cuidadoso, envolvendo afetos, responsabilidades, dando a sexualidade identidades e ao mesmo tempo colocando-a no lugar de um saber não total izado - ainda a se construir uma vez que ela é plástica e mutante assim como os sujeitos que a constitui.

N esta direção ressal ta-se que a adoção de práticas educativas voltadas para a orientação sexual, solicita que continuamente os educadores revejam seus conhecimentos, valores e comportamentos. Os educadores necessitam de preparo técnico e relacional que inclui entre outros, o lidar com adolescentes, 0 trabalhar com a sexualidade num enfoque biopsicossocial e dominar elementos de um processo educativo libertador e que não acarrete a supressão do tema em seu conteúdo programático(11).

Os discursos a seguir atestam um conteúdo que reitera o dispositivo da sexualidade, originando omissões, constrangimentos, inter dições:
[ ...] o PCN da primeira a quarta série ta aí [ ...] tem educação sexual, mas nós não trabalhamos [ ...] tem os livros, mas eu nem abro [ ...] (A 1).

\section{[ ...] eu escondi o meu [ ...] (A5).}

0 exercício da sexual idade acopla-se a determinações que escapam ao ditame moder no de seu valor intrínseco ${ }^{(12)}$. A omissão consciente ou a dúvida de sua capacidade inter na e técnica para a orientação sexual devem ser questionadas e revisadas, tanto as posturas da escola quanto do educador. 0 discurso veicula e produz poder; de modo semel hante o silêncio e o segredo dão guarida ao poder, fixando suas interdições ${ }^{(13)}$.

Qualquer educador pode, a princípio, trabaIhar com orientação sexual, sendo necessário que esteja acessível ao conhecimento do outro e de si próprio. É necessário haver condescendência consigo mesmo, não estabelecer uma relação arrogante com o saber científico, ter disponibilidade para rever atitudes e crenças. Observa-se, no entanto predomínio de obediência às normas e não uma vontade inter na ${ }^{(9) ;}$; [...] esse tipo de poder somente teria a potência do não incapacitado para produzir, apto apenas a colocar limites, seria essencialmente anti-energia; esse seria o paradoxo de sua eficácia; nada poder senão o que Ihe permite"(13), como observado no depoimento:

[ ...] minha filha que tem oito anos veio me fazer umas perguntas sobre essas coisas e eu disse que quando ela for maior, ela vai ficar sabendo [ ...] se a escola mandar eu falar disso pros alunos eu falo [ ...] mas com a minha filha não [ ...] (A4).

$\mathrm{N}$ ota-se sentimentos conflitantes entre 0 que Ihe é ordenado fazer e o que acredita ser de fato correto com sua formação histórico-social. A temática se associa a questões complexas, de aspectos existenciais e institucionais onde várias vezes os educadores não sabem lidar com a questão em suas próprias vidas. $N$ ão se pode exigir do educador um desprendimento absoluto no que tange as questões associadas à sexualidade, mas sim, consciência sobre quais os val ores, crenças, opiniões esentimentos que apreendeu para que desenvolva uma postura ética na sua atuação junto aos alunos ${ }^{(14)}$.

A o se observar as atitudes dos educadores investigados, em sua totalidade composta por muIheres, evidencia-se que a experiência da sexualidade permanece ainda profundamente marcada por 
padrões sexuais que estruturam tanto as condutas durante a vida quanto suas percepções diante do significado de sexualidade ${ }^{(12)}$. N ota-se subjetivamente no depoimento a seguir não somente a repressão da sexualidade, mas também uma intensificação da inquietação dos prazeres:

[ ...] sexo? acho muito er rado falar disso. E 0 amor? A cumplicidade? Sexo éentrega para al guém que confiamos nosso corpo pra procriação [ ...] (A3).

O sentimento amoroso nesse discurso sugere um aprofundamento da intimidade, solicitando cumplicidade, que teria como meta a procriação. Essa afirmativa é fortalecida com a explicação de que "o amor romântico suscita a questão da intimidade, sendo incompatível com a luxúria" e que tal amor romântico "apóia-se no outro e idealiza o outro, e projeta um curso do desenvolvimento futuro"(15). É apontado ainda, como um processo ideológico que conduza a uma progressiva reaproximação do moral, pressupondo dimensões valorativas das práticas sexuais. N ota-se que não é explicitada nenhuma manifestação da vontade, do desejo, mas, sobretudo um modo de ver a sexualidade, desentranhada de um modelo proposto de vida sexual.

Percebe-se que a relação sexualidade versus reprodução perdura como um modo de pensá-la, não apenas como efeito ou produto final de outras instâncias, mas observável na prática sexual dos indivíduos, isto é, como comportamento ou atividade sexual. O utro ponto a ser destacado refere-se à associação entre sexo e amor, pois essa relação sempre foi constitutiva de sexual idade, o que deve ser considerado é que a sexualidade não é fixa, seus significados e conteúdos podem variar ao longo da história assim como ao longo da vida dos indivíduos $^{(12)}$.

A diferença entre sexo e sexualidade passou a ter outro sentido quando foi apontada e caracterizada a necessidade de desejo e de prazer. 0 sexo éa característica biológica, hereditária, que distingue fisicamente o homem da mulher e para o senso comum o sexo é visto como a relação sexual e os órgãos genitais. De modo predominante a sexualidade é interpretada como tudo que diz respeito à genitalidade onde se confunde com o sexo:

[ ...] a maior dificuldade, éque o sexo évisto como algo feio [ ...] éum problema decultura, do meio [ ...] (A 1).
Essa visão da sexualidade limitada e cerceada não é uma idéia "a priori"; certamente é um produto de toda uma cultura que perpetua os interesses sociais a partir de uma realidade dada, submetendo o sujeito social a se "adaptar" ao que é préexistente, sem oportunidade de transformação ${ }^{(16)}$. E ste paradigma vai determinar o "jeito de olhar" e de "fazer" dos sujeitos:

[ ...] o quetem éuma banalização do sexo [ ...] ol ha só a propaganda do carnaval do M inistério da Saúde [ ...] um casal no car naval encostado no muro e começando a fazer [ ...] fala decamisinha, decomo conseguir [ ...] isso já ta desper tando nos adolescentes a vontade [...] não acho que isso educa isso faz é eles quererem mais é fazer o que a televisão ensina [ ...] (A6).

I dentifica-se nesse discurso um posicionamento oponente e de censura à propaganda de prevenção as DST / aids do M inistério da Saúde por esta não fazer parte da realidade deste sujeito ou de sua vida anterior. A inda, infere que as infor mações incitam o desejo dos jovens em relação ao sexo.

F alar ou pensar uma situação distante da qual se vivencia, pode favorecer uma compreensão dialética da realidade - o sujeito se posiciona contrário por falta de vivência/ conhecimento prático da situação, e assim a transforma; transforma-se ou simplesmente ignora a realidade; seria a "intrusão de eventos distantes na consciência cotidiana" que se organiza em torno dos eventos que se tem consciência, remetendo a uma anástrofe da realidade, onde o objeto ou evento real, quando descoberto, sugere ter uma experiência menos concreta que sua própria representação(17).

No depoimento abaixo, percebe-se que 0 educador sendo adulto e agente formador ainda tem resistências em discutir papéis de "adulto", o que pode ser esclarecido quando relaciona a sexualidade em uma rede intrincada de poder, submetendo-a ao poder por uma razão política, econômica e social. N esta situação, o sujeito em evidência, demonstra certo poder em decidir pela inclusão ou não do tema sexual idade ${ }^{(13)}$.

[ ...] esse éum tema [ sexualidade] super complicado da gente discutir [ ...] . As coisas de adulto são muito complicadas, deixa isso pra lá [ ...] (A 4).

A crescenta-se aos posicionamentos manifestos, e não tão menos importante, uma fragmentação da construção e responsabilização individual, 
retratada pela omissão e insuficiente compromisso social:

[ ...] muitos diretores dizem: "passando do portão não é mais problema da escola" [ ...] (C1).

[ ...] a gente acaba deixando de lado [ ...] eu já tenho problema demais, a filha da professora ta lá com problema de gravidez, então elejá tem tanto problema em casa que não quer se envolver com outro [ ...] (C4).

[ ...] a mãeveio procurar, o queéquea diretora deveria ter feito, ter sentado vamos conversar, por que o que ela queria era uma orientação, ela cortou pela raiz a orientação, mesmo que 0 caso não tivesse acontecido dentro da escola, não fosse um problema da escola, era pra ter conversado com a mãe e ter orientado [ ...] (C2).

A noção de sujeito é permeada por alter ações significativas no espaço social externo dos indivíduos assim como nas instituições, não havendo separação da vida pessoal, das circunstâncias sociais. $N$ esse sentido, o mundo desdobra-se muito além dos campos das atividades individuais e dos compromissos pessoais, aludindo que haja um ato processual de intervenções e transformações ativas para um encontro de si mesmo e de suas práticas ${ }^{(17)}$.

As relações são percebidas como perigosas, causando certa ansiedade e como apontado nos discursos anteriores, os educadores refugiaram-se em uma espécie de apatia resignada frente às manifestações de seu entorno e comunidade escolar, em uma quase ausência de consciência da constituição reflexiva de sua atividade e das implicações em seu cotidiano. Considera-se que esteja ocorrendo um impasse individualista, onde o "eu" não está vinculado ao "nós" e em tal situação, o indivíduo encontrarse-ia inserido nas formas de social ização, mas sem nunca ser por el as completamente deter minado ${ }^{(18)}$.

Quando o discurso refere que "[ ...] passando do portão não é mais problema da escola [ ...]", entende-se que esteja havendo um "desencaixe" das instituições e de seus papéis sociais, com uma separação gradual de funções e de espaços/ local, para as intervenções mais amplas da educação. T al posicionamento resulta em falta de compromisso, decorrente da ignorância do papel social, assim como da limitação aparente de capacidade técnica, afetando diretamente as relações sociais e profissionais. Poucas pessoas sustentam uma segurança íntima invariável nos sistemas de conhecimento técnico que os afetam, e todos, conscientes ou não, escolhem entre as possibilidades concorrentes da ação que tais sistemas (ou abandono deles) podem oferecer $^{(17) .}$.

Contudo, quando tais posicionamentos são colocados em foco, mais os conhecimentos se tor nam embaçados para os indivíduos e para a sociedade na qual se inser em e consequentemente menor será a probabilidade desses sujeitos anteverem as consequências da omissão de seus atos, para al ém da esfera de sua particularidade.

\section{CONSIDERAÇÕES FINAIS}

N este estudo, em que se buscou por meio da escuta das vozes dos educadores, como o tema orientação sexual vem sendo inserido em seu cotidiano, foi possível conhecer e retratar a linguagem e as práticas institucionais.

A transversalização do tema é um discurso oficial imposto por uma política educacional nacional, porém, nas suas estruturas organizacionais ainda não foi incorporada de fato. D e maneira dispersa há entre os atores da pesquisa, uma forte tendência a considerar que a escola seja de fato, um lugar ideal para trabalhar com temas relacionados à sexualidade.

Reconhece-se um esforço em privilegiar temas relativos à orientação sexual, embora os educadores admitam que a falta de preparo técnico/ emocional interfira na efetivação e aprofundamento desse conteúdo, abordando-os apenas em situações pontuais as quais se deparam no cotidiano escolar. N otou-se a presença de sentimentos e posicionamentos conflitantes em relação à abordagem da temática sexualidade - imposição profissional e desejo pessoal; tendo sido mencionado atitudes de supressão deste conteúdo no processo pedagógico.

Persiste uma visão reducionista sobre sexualidade, que na voz dos educadores ecoa enquanto fator de risco para o humano, com forte predominância do componente biológico da sexualidade, privilegiando apenas questões ligadas aos agravos decorrentes da iniciação sexual.

As fragilidades identificadas reforçam a ideia de que programas e/ ou projetos de inter venção que na prática traduzem uma orientação e uma decisão política previamente tomada, não garantem sua execução/ implantação, exigindo a compreensão do contexto que molda e condiciona as representações dos atores. 
Com um discurso de proteção sexual embutido subliminarmente nos PCN 's, permitiu-se deduzir que a informação, dependendo da maneira que será transmitida, pode tornar-se um el emento complicador na busca pela compreensão e exploração das identidades sexuais, das relações com 0 desejo e o prazer. A credita-se que deva haver sim, uma informação direcionada ao cuidado de si, porém, essa orientação deverá extrapolar os limites preventivistas, para caracterizar-se como produção de um saber amplo da sexualidade.

O portunamente, propõe-se que a orientação sexual seja abordada nas salas de aula, de maneira problematizadora, reflexiva e que sejam (re)pensadas as "verdades"; nessa direção, educadores e alunos teriam a possibilidade de desvendar outros univer sos distintos dos seus.

Conclui-se, portanto, que a temática "orientação sexual" requer uma abordagem extensiva, inclusiva no sentido de construir uma rede integrada e interdisciplinar (órgãos gestores, organizações civis, saúde, instituições de ensino superior) de modo sistemático e contínuo, favorecendo um (re)conhecimento do assunto pel os educadores, almejando com isso a busca pela ética, pela cidadania e pelos direitos humanos e sociais.

\section{REFERÊNCIAS}

1 M inistério da E ducação (BR ). Lei no 9.394, de 20 de dezembro de 1996: estabelece as diretrizes e bases da educação nacional. Brasília (D F); 1996.

2 Sampaio AT L, T imóteo R PS, E nders BC. E ducação sexual no contexto da escola. Carpe D iem. 2007;5:17397.

3 Bardin L. Análise de conteúdo. Lisboa: E dições 70; 2009.

4 M inistério da Saúde (BR), Conselho Nacional de Saúde. Resolução 196, de 10 de outubro de 1996: diretrizes e normas regulamentador as de pesquisa envolvendo seres humanos. Brasília (DF ); 1996.

5 M inistério da E ducacão (BR), Secretaria de E ducação $\mathrm{F}$ undamental. Parâmetros cur riculares nacionais: introdução aos parâmetros curriculares nacionais. Brasília (DF); 1997.

\section{Endereço da autora/ Dirección del autor / Author's address:}

Sandra A parecida de A Imeida

Av. das F alésias, s/ n., Condominio V illage Atlântico Sul, casa A4, Ponta do Seixas

58045-670, João Pessoa, PB

E-mail:sandra_almeida09@yahoo.com.br
$6 \mathrm{M}$ arin AJ. Com o ol har nos professores: desafios para o enfrentamento das real idades escolares. Cad CE DES [ I nternet] . 1998 [ citado 2009 abr 05] ;19(44):818. D isponível em: http:/ / www.sciel o.br/ sciel o.php? script $=$ sci arttext $\&$ pid $=S 0101-3262199800010000$ 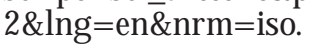

7 Gagnon JH. U ma interpretação do desejo: ensaios sobre o estudo da sexualidade. Rio de Janeiro: $G$ aramond; 2006.

8 Vitiello N. Sexualidade: quem educa o educador: um manual parajovens, pais e educadores. São Paul o: I glu; 1997.

9 T eixeira F ilho FS, Santis M B, Silva R G. Corpo, afecto e sexualidades: capacitando professores para o trabaIho com a educação sexual nas escolas [ I nternet] . N úcl Ens. 2003 [ citado 2008 abr 03] ;1:141-54. Disponível em: http:// ww w.unesp.br/ prograd/ P D F N E 2002/ corpo\%20afecto.pdf.

10 Aquino J G, organizador. Sexualidade na escola: alternativas teóricas e práticas. São Paulo: SU M U S; 1997.

11 M andú ENT, Corrêa ACP. E ducação sexual formal na adolescência: contribuições a construção de projetos educativos. Acta Paul Énferm. 2000;13(1):27-37.

$12 \mathrm{H}$ eilbor $\mathrm{M} \mathrm{M} \mathrm{L}$, organizadora. Sexualidade: 0 ol har das ciências sociais. Rio de Janeiro: Zahar; 1999.

13 F oucault M. H istória da sexual idade. Rio de Janeiro: Graal; 1988.

14 W arken R. A escola e a sexualidade [ I nter net] . F Iorianópolis: GLSSIT E; 2007 [ citado 2007 abr 25]. D isponível em: http:/ / www.glssite.com.br/ edusex/ edusex/ escolaesexualidade.htm.

$15 \mathrm{G}$ iddens A. A transfor mação da intimidade: sexual idade, amor e erotismo nas sociedades modernas. $2^{\underline{a}}$ ed. São Paulo: U N E SP; 1993.

16 Salla LF, Q uintana A M . A sexual idade enquanto tema transversal: educadores e suas representações [ Internet] . [ S.I.] : Pedago Brasil; [ 200-] [ citado 2008 out 10]. Disponível em: http:// www.pedago brasil.com.br/ psicologia/ asexualidade.htm.

17 G iddens A. M odernidade e identidade. Rio de J aneiro: Jorge Zahar; 2002.

18 Perrusi AFA, Franch M. Disciplina sexualidade e saúde [ notas de aula] . João Pessoa: Centro de Ciências H umanas, L etras e A rtes, U niversidade F ederal da Paraíba; 2009.

Recebido em: 30/ 12/ 2010

A provado em: 26/ 02/ 2011 